\title{
A relação entre os saberes comunitários e os conteúdos escolares no processo de alfabetização
}

\section{The relation amongst communitary knowledge and scholastic contents in process of alphabetization}

\author{
Jaqueline Santos PICETTI \\ Luciane Magalhães Corte REAL
}

\begin{abstract}
RESUMO
Esse artigo é um dos produtos da pesquisa "Os Movimentos de Exclusão Escolar Oculta", realizada nos anos de 2000 a 2002, junto ao Programa de Pós-Graduação em Educação da Universidade Federal do Rio Grande do Sul. Essa se caracterizou como um estudo qualitativo, onde durante sete meses coletou-se os dados, utilizando a observação participante, a entrevista oral semi-estruturada e a análise documental. O campo empírico foi composto de professores e alunos de cinco turmas de Alfabetização de uma Escola Municipal de Porto Alegre. No decorrer da análise de dados, foram elaboradas três dimensões - epistemológica, desenvolvimento moral e relação entre os conhecimentos comunitários e os conteúdos escolares - a partir das quais foi construído o conceito de Exclusão Escolar Oculta. Nesse artigo, refletiremos a partir da questão teórica estudada na última dimensão citada, utilizando o referencial teórico de Paulo Freire. Procuraremos demonstrar que a concepção de Educação Bancária permanece oculta na Rede Municipal de Ensino de Porto Alegre.
\end{abstract}

Palavras-chave: alfabetização, exclusão escolar, saberes comunitários, sala de aula.

\begin{abstract}
This article is one of the products of a research named "Movements of Hidden Scholar Exclusion". This research was realized between the years 2000 to 2002, as part of a Pos-graduation in Education, at Federal University of the State of Rio Grande do Sul, in Brazil. It has as a characteristic to be a qualitative study. For seven months data was collected, using the method of participating observation, semi-structured oral
\end{abstract}


interviews and documental analysis. The empirical field was composed of teachers and students of five classes of alphabetization, in a municipal school of Porto Alegre. As data were analyzed, three dimensions came out: epistemological, moral development and relation amongst communitarian knowledge and scholastic contents, this being a point of departure to construct a concept of Hidden Scholar Exclusion. On this article we will have to think over the theoretical question that was studied, using theoretical reference of Paulo Freire. We will try to show that the concept of "Banking Education" remains hidden in municipal net of education of Porto Alegre.

Index Terms: alphabetization, classroom, communitarian knowledge, scholar exclusion.

\section{Introdução}

Esse artigo é um dos produtos da pesquisa "Os Movimentos de Exclusão Escolar Oculta", realizada nos anos de 2000 a 2002 junto ao Programa de Pós-Graduação em Educação da Universidade Federal do Rio Grande do Sul. Essa se caracterizou como um estudo qualitativo, onde durante sete meses coletamos os dados utilizando a observação participante, a entrevista oral semi-estruturada e a análise documental. O campo empírico foi composto de professores e alunos de cinco turmas de Alfabetização de uma Escola Municipal de Porto Alegre. Consideramos relevante destacar que as Escolas Municipais de Porto Alegre têm como a meta fundamental garantir a aprendizagem, tendo como objetivo a construção de uma sociedade sem exclusão e voltada para os interesses da maioria (SMED, 1999).

No decorrer da análise de dados, elaboramos três dimensões de análise - epistemológica ${ }^{1}$, desenvolvimento moral $^{2}$ e relação entre os

\footnotetext{
${ }^{1}$ A dimensão referida diz respeito à epistemologia presente na prática e no discurso das professoras, onde pesquisamos as conseqüências veladas das epistemologias aprioristas e empiristas presentes na sala de aula, das quais as professoras não têm consciência e que estão inseridas numa proposta político-pedagógica que tem como principais referenciais teóricos Piaget, Vygotsky, Wallon e Freire, propondo uma prática interacionista.

${ }^{2}$ Essa dimensão diz respeito à forma como a autonomia vem sendo trabalhada dentro das Escolas Municipais de Porto Alegre e em que medida a transmissão de valores e a imposição de certos comportamentos ainda estão presentes no cotidiano escolar, classificando muitas crianças como
} 
conhecimentos comunitários escolares e os conteúdos escolares ${ }^{3}$ — a partir das quais construímos o conceito de Exclusão Escolar Oculta. O fenômeno da Exclusão Escolar Oculta ocorre nas relações entre professores e alunos por meio das falas, dos gestos e dos olhares vivenciados em sala de aula, no restante do ambiente escolar e nos momentos de avaliação. Caracterizamos essa exclusão como oculta, pois não se efetua, mesmo porque não pode, pelas vias formais e documentais, como ocorria anteriormente na década de 1980 e pesquisada por Patto (1991) e Dorneles (1986). Atualmente há leis (BRASIL, 1990, 1996) que falam da permanência do aluno na escola e do trabalho de inclusão que deve ser feito. Sendo assim, essa exclusão, da qual tratamos na pesquisa, pode ficar imperceptível a algumas pessoas, e às vezes, até mesmo à própria professora que exclui, porque ela pode não perceber as conseqüências de suas ações (PICETTI, 2002). Na pesquisa citada, procuramos mostrar "o pôr de lado", "abandonar", "eliminar", existentes nas relações professor-aluno na sala de aula e no ambiente escolar e, como já dito anteriormente, muitas vezes, não percebido ou compreendido pelas pessoas envolvidas no processo como um movimento excludente.

Nesse artigo, priorizaremos a dimensão de análise da relação entre os conhecimentos comunitários escolares e os conteúdos escolares, refletindo sobre os Movimentos de Exclusão Escolar Oculta presentes no processo de alfabetização a partir do referencial teórico de Paulo Freire.

\section{Escrevendo a vida}

Para iniciarmos a presente discussão, torna-se significativo abordarmos a análise de Ernani Maria Fiori sobre as importantes relações

inadequadas e indesejadas nesse ambiente. Designamos como dimensão de construção moral e a elaboramos a partir das idéias de Piaget sobre o desenvolvimento da autonomia.

3 Nessa terceira dimensão procuramos entender como tem se estabelecido ligações na escola entre os conhecimentos informais, que a criança constrói no âmbito familiar e comunitário, e os formais, trabalhados na instituição, e constatamos que a não-relação ou a própria desconsideração da cultura popular pode caracterizar-se como movimentos de exclusão escolar oculta. 
entre o processo de construção da escrita e os saberes comunitários, que consta no prefácio do livro Pedagogia do Oprimido, de Paulo Freire (2000c, p. 10). Ele nos diz que: "Talvez seja este o sentido mais exato da alfabetização: aprender a escrever a sua vida, como autor e como testemunha de sua história, isto é, biografar-se, existenciar-se, historicizar-se."

O trabalho com crianças de seis, sete, oito anos ou com adultos em processo de alfabetização deve ir além da decodificação de palavras: é necessário ler e escrever com sentido, o sentido na vida. $\mathrm{O}$ aluno deve articular essa aprendizagem em seu mundo, ou seja, o da comunidade em que vive. Utilizá-la como forma de comunicação e ampliação da leitura de mundo.

A pesquisa com caráter sociológico e antropológico proposta pela Secretaria Municipal de Educação de Porto Alegre, como importante instrumento na elaboração do planejamento, pode ser entendida como fonte de conhecimentos que darão sentido ao processo de alfabetização das crianças e dos adultos, pois é a partir dessa pesquisa realizada na comunidade de seus alunos cujos professores entrarão em contato com os saberes comunitários, e podendo relacioná-los com os conteúdos escolares. Fiori também afirma:

Ensinar a ler as palavras ditas e ditadas é uma forma de mistificar as consciências, despersonalizando-as na repetição - é a técnica da propaganda massificadora. Aprender a dizer a sua palavra é toda a pedagogia, e também toda a antropologia. (apud FREIRE, 2000c, p. 18)

Podemos ampliar nossa discussão com as contribuições de Freire e Beto (2001) no livro "Essa Escola Chamada Vida", onde eles expõem a seguinte idéia sobre a construção da leitura:

Toda leitura da palavra pressupõe uma leitura anterior do mundo, e toda leitura da palavra implica a volta sobre a leitura do mundo, de tal maneira que "ler mundo" e "ler palavra" se constituam um movimento em que não há ruptura, em que você vai e volta. E "ler mundo" e "ler palavra", no fundo, para mim, implicam "reescrever" o mundo. Reescrever com aspas, quer dizer, transformá-lo. A leitura da palavra deve ser inserida na compreensão da transformação do mundo que 
deve remeter-nos, sempre, à leitura de novo do mundo. (FREIRE; BETO, 2001, p. 15)

No processo de alfabetização é imprescindível que a leitura e a escrita da palavra impliquem uma releitura crítica do mundo como “caminho" para transformá-lo. É a compreensão da linguagem e do seu papel na conquista da cidadania. É a linguagem como caminho de invenção da cidadania (FREIRE, 2000a).

O conteúdo programático da educação, nesse caso a alfabetização, necessita partir de situações presentes, existenciais, concretas, e que reflitam as aspirações dos alunos. É preciso promover em sala de aula uma alfabetização que estabeleça interlocuções com a reflexão crítica sobre as relações pessoas-mundo e pessoas-pessoas. Os alunos devem ser sujeitos do seu pensar, discutindo-o e refletindo sobre sua visão do mundo (FREIRE, 2000c). As letras, as palavras, os textos, as histórias constituem janelas para a compreensão da comunidade em que vivem e da visão que possuem dela.

$\mathrm{O}$ educador necessita ler, cada vez melhor, a leitura de mundo que o grupo no qual atua faz do seu contexto, considerando o "saber de experiência feito". A explicação do mundo desses grupos faz parte da compreensão que possuem da sua própria presença nele. (FREIRE, 2000b)

As crianças de classe popular, assim como as das demais classes, necessitam de uma escola que leve a sério seus interesses e peculiaridades comunitárias, na qual o professor organiza o tempo e a planificação dos temas favoravelmente aos interesses e características dessa cultura (FREIRE; NOGUEIRA, 2001). Contudo, é importante destacar que, partir do saber dos educandos, não significa ficar girando em torno dele. É partir do "saber de experiência feito" para superá-lo (FREIRE, 2000a). No livro Pedagogia da Autonomia, Freire (1999) retomou essa questão, lembrando a necessidade do educador debater com os educandos a razão de ser dos saberes comunitários e sua relação com o ensino dos conteúdos escolares. 'Por que não estabelecer uma necessária 'intimidade' entre os saberes 
curriculares fundamentais aos alunos e a experiência social que eles têm como indivíduos?” (FREIRE, 1999, p. 34).

Freire e Beto (2001) explicitam claramente essa questão numa passagem do livro "Essa Escola Chamada Vida", mencionando que:

[...] como educadores e políticos, e políticoseducadores, trabalhando com as massas populares, ou partimos dos seus níveis de compreensão da realidade, do sonho das massas populares, ou estaremos impondo-lhes o que nos parece melhor para elas. (FREIRE; BETO, 2001, p. 75)

Podemos nos aprofundar nesse aspecto a partir da idéia expressa também por Freire (2000a), na Pedagogia da Esperança:

O respeito, então, ao saber popular implica necessariamente o respeito ao contexto cultural. A localidade dos educandos é o ponto de partida para o conhecimento que eles vão criando do mundo. 'Seu' mundo, em última análise é a primeira e inevitável face do mundo mesmo (FREIRE, 2000a, p. 86).

A imposição da visão de mundo do educador é chamada por Freire (2000c) de invasão cultural e ocorre a partir do desrespeito às potencialidades dos alunos, inibindo-lhes a criatividade e a expansão. Para ele, essa invasão cultural é uma característica da ação antidialógica, onde só o professor tem voz e vez. "Quando entro em uma sala de aula devo estar sendo um ser aberto a indagações, à curiosidade, às perguntas dos alunos, a suas inibições; um ser crítico e inquiridor, inquieto em face da tarefa que tenho - a de ensinar" (FREIRE; NOGUEIRA, 2001, p. 52). Ensinar não é transmitir conhecimentos, mas sim produzir condições de aprender criticamente.

O afeto e o reconhecimento não são suficientes no trabalho com educação, são necessárias competência e consciência política para preencher o espaço da escola e orientá-lo aos problemas trazidos pela Cultura Popular (FREIRE; NOGUEIRA, 2001). Ser educador é perceber-se como alguém que "influencia" a formação dos alunos como futuros cidadãos críticos ou os leva a tornarem-se seres submissos a uma classe de opressores. O espaço de 
construção do conhecimento deve contar com a presença de educadores e educandos inquietos, instigadores, criadores, curiosos, humildes e persistentes (FREIRE, 1999). Para Freire e Betto (2001), o educando é o protagonista do processo educativo e o educador é a pessoa que vai ajudar a explicitar e sistematizar o que a vida e o contexto dos educandos fornecem como elemento.

Se os educadores conseguissem notar que foi aprendendo que se tornou possível perceber que se poderia ensinar, provavelmente compreenderiam a importância das experiências informais, vivenciadas nas ruas, nas praças, no trabalho, nas salas de aula, nos pátios dos recreios e em outros espaços (FREIRE, 1999).

A metodologia dialética tem como ponto de partida a prática social dos educandos. É em torno dessa prática social que girará o processo educativo. "O aprendizado comum, que liga teoria e práxis, só se dá a partir da realidade coletivamente refletida" (FREIRE; BETO, 2001, p. 77).

$\mathrm{Na}$ pesquisa "Movimentos de exclusão escolar oculta" (PICETTI, 2002) foi construída uma trajetória psicopedagógica de análise e reflexão sobre o fenômeno da Exclusão Escolar Oculta, com a intenção de investigar sua existência e finalidade de contribuir para a educação na busca de novos olhares em relação aos alunos e alunas.

Nessa pesquisa, procuramos aprofundar a reflexão sobre esse fenômeno em turmas de alfabetização, enfocando uma análise social. Procuramos ultrapassar a análise da construção moral (no sentido comportamental, tão destacado nas escolas), refletindo também sobre a epistemologia que fundamentava a ação pedagógica e as relações que eram estabelecidas no planejamento e na prática em sala de aula entre os saberes comunitários e os conteúdos escolares, tendo como principal fonte teórica as idéias de Jean Piaget e contribuições de Paulo Freire, bem como de outros estudiosos que compartilham dessas teorias. 
A análise dos dados, com base no estudo sobre as contribuições de Freire, destacadas nas páginas anteriores, confirmara a existência da Exclusão Escolar Oculta através da desconsideração dos saberes comunitários na escola durante o processo de alfabetização. Como exemplo citamos a descrição de uma das salas de aula pesquisada:

Na parede, acima do quadro, havia o alfabeto feito pela professora com desenhos retirados de livros. As palavras utilizadas eram distantes do contexto e vocabulário vividos pelas crianças. Um exemplo significativo é o uso da palavra "navio" para a letra "n". Sabe-se que as crianças dessa turma dificilmente saem do bairro em que moram e, portanto, algumas nunca viram um navio, a não ser pela televisão (PICETTI, 2002, p. 129).

Tal fato também pode ser visto na entrevista com as crianças:

RODRIGO (o nome das crianças pesquisadas foi modificado, para que não pudesse ocorrer qualquer identificação das mesmas) escrever?

Por que será que a gente precisa aprender a ler e

- Prá trabalhá.

VERA

Por que a gente precisa aprender a ler e a escrever? quisé.

- Ah, depois do ano que vem já pode sê tudo que

\section{LARISSA}

Por que a gente precisa aprender a ler e a escrever?

- Prá quando crescê pra sabê lê e escrevê.

MARCOS

Por que a gente precisa aprender a ler e a escrever?

- É prá, prá gente sê alguma coisa na vida quando a gente crescê. O que que tu qué sê, tu já sabe.

DEISE

E por que a gente precisa aprender o abcd?

— Pra crescê e fazê as coisas. (PICETTI, 2002, p. 130)

Os saberes comunitários, as idéias, os pensamentos, as reflexões e as sugestões das crianças foram desconsiderados nos momentos de planejamento e avaliação das turmas pesquisadas. Durante a entrevista com uma das professoras pesquisadas, o fato da não-utilização dos conhecimentos comunitários no planejamento surgiu quando eram feitas as seguintes perguntas:

Como você organiza seu planejamento? O que você tem como prioritário para seu ano-ciclo? Que relações estabelece 
com a pesquisa sócio-antorpológica? A professora respondeu: Em poucos momentos estabeleço relações do meu planejamento com a pesquisa sócio-antropológica, eu priorizo a alfabetização, né? A leitura, a escrita, o pensamento lógicomatemático, e realmente as discussões sobre a pesquisa sócioantropológica surgem em situações cotidianas, assim, de um assunto que surge, alguma coisa que eu vá conversar com as crianças, mas não é nada que permeie o dia a dia. (PICETTI, 2002, p. 129)

Analisamos duas turmas das cinco pesquisadas, isto é, o trabalho de coleta de dados ocorreu em cinco turmas e em cada uma observamos questões diferentes sobre o fenômeno da Exclusão Escolar Oculta, em algumas, mais acentuado, e, em outras, nem tanto, mas todas tinham movimentos que caracterizavam o que pesquisávamos. Procuramos construir um caminho de reflexão a partir de um contexto maior (as cinco turmas) e fazer um recorte, para que o trabalho fosse mais enriquecedor. Pudemos pensar e analisar as turmas em que o fenômeno mais se salientava. Um recorte prévio, isto é, a escolha das turmas antes do trabalho de campo, poderia impossibilitar um estudo mais aprofundado e detalhado, porque se limitaria ao que fosse coletado. Das cinco turmas uma destacou-se devido ao fato de a grande maioria das crianças entrevistadas relatar que sua professora gritava e xingava, bem como comentar que discordavam da maneira como ela as tratava, castigando e enviando para a direção quem incomodava e não ficava em silêncio em sala de aula. Essa constatação foi bastante pertinente, pois Piaget (1994), em suas pesquisas, demonstra que dificilmente uma criança nessa faixa etária discorda da atitude de um adulto, pois acredita que ele sempre tem razão. Além disso, essa turma, que nomeamos de turma A, também se destacou por ter sido a que mais teve alunos faltosos no final do ano (de 25 alunos, 7 eram faltosos). A outra turma, que nomeamos de turma $\mathrm{B}$, foi escolhida, principalmente, por ter como professora a que mais fez comentários embasados em uma epistemologia apriorista durante as avaliações das crianças. As consequiências da sua forma de pensar puderam ser acompanhadas nas 
observações em sala de aula, onde ela geralmente salientava e elogiava a participação das crianças que considerava que teriam sucesso no processo de alfabetização. Às que ela acreditava já estarem fadadas ao fracasso, dirigia olhares, gestos e falas de descrença.

Tanto na turma A quanto na turma B observamos que a sala de aula consistia em um espaço configurado apenas pelas professoras e por seus conhecimentos, no qual as crianças deviam se adequar, permanecendo em silêncio para aprender os conteúdos de alfabetização, não possuindo qualquer relação com a realidade em que viviam. Freire (2000c), no livro "Pedagogia do Oprimido", chamou a atenção para o fato dos alunos de classes populares, ao terem seus conhecimentos desconsiderados e, algumas vezes, menosprezados pela escola, poderem se convencer de que são incapazes, acreditando ser o professor o depositário de todos os conhecimentos.

$\mathrm{Na}$ presente investigação isso caracterizou um dos movimentos de Exclusão Escolar Oculta, pois os saberes das crianças eram desconsiderados no espaço escolar e elas acabavam confusas também quanto ao sentido da alfabetização, o que foi comentado a partir de Fiori (apud FREIRE, 2000c) o qual deveria ser o de aprender a escrever a sua vida e aprender a dizer a sua palavra.

Acreditamos que ficou muito claro que o sentido da alfabetização afirmado por Fiori estava longe das turmas observadas. Nos espaços investigados, o trabalho de alfabetização desenvolveu-se através da escrita de palavras que geralmente eram desconhecidas na comunidade. A produção textual não foi utilizada em nenhuma das duas turmas. Conforme observamos, a aprendizagem não tinha muito sentido para os alunos, pois não compreendiam em que esse conhecimento iria ajudá-los e relatavam que seria utilizado no futuro.

$\mathrm{Na}$ entrevista que realizamos com vinte e duas crianças da turma A, apenas nove falaram sobre o sentido da aprendizagem da leitura e da escrita, 
pois o assunto foi muito difícil de ser abordado, porque elas estavam muito centradas no comportamento em sala de aula. Muitas perguntas eram respondidas com a maneira que deveriam ser e se portar em aula. Das nove, seis relacionaram a aprendizagem com o futuro, mas elas não sabiam bem o que isso queria dizer, pareciam repetir o discurso que ouviam dos adultos como pudemos observar nas respostas das crianças, citadas anteriormente, sobre os motivos pelos quais devemos aprender a ler e a escrever.

Supomos, a partir dessas falas, que a aprendizagem não tinha muito sentido para elas, pois, como já dito, o futuro estava muito distante e não compreendiam muito bem em que esse conhecimento iria ajudá-las.

Outras três crianças relacionaram a aprendizagem da leitura e da escrita com o passar de ano, mas a idéia era um tanto surpreendente, pois a proposta de estudos da escola em que freqüentavam, uma Escola Municipal de Porto Alegre, não prevê tal critério como forma de aprovação ou reprovação. Pareceu-nos que as crianças da turma A não compreendiam o sentido de estarem se alfabetizando.

Essa questão também foi constatada na turma B a partir da fala das crianças quando as questionamos sobre esse assunto:

\section{JANINE}

O que tu aprendes na escola?

- Várias coisa, eu aprendo a escrevê, a lê, também aprende a sabê mais.

E por que a gente precisa aprender a ler e a escrever?

- Pra quando crescê, quando se quisé pegá um ônibus não vai sabê, não vai sabê lê, vai tê que perguntá pras otras pessoas o que tava escrito.

\section{LUIZA}

Conta para ela por que é importante a professora passar texto para vocês copiarem?

- Que daí a gente aprende a lê e aprende mais.

E por que a gente precisa aprender a ler?

- Pra sê alguma coisa na vida.

PAULINA

Conta para ela, o que a gente pode aprender na aula?

- A gente pode aprendê a lê, a escrevê.

E por que a gente precisa aprender a ler e a escrever?

— Porque senão quando a gente sê grande a gente vai sê burra, não vai sabê nada.

TELMO 
Por que é importante a gente aprender a ler e a escrever? Porque quando a gente precisá, se a gente não tivé ido na escola, a gente precisá umas vez no serviço, a gente não vamo sabê. (PICETTI, 2002, p. 133).

Novamente presenciamos o distanciamento entre os conteúdos escolares e os saberes comunitários. O sentido da aprendizagem da leitura e da escrita estava colocado no futuro, sem nenhuma utilidade no presente. Nesse futuro, a escrita e a leitura teriam um sentido restrito de sobrevivência (emprego, pegar um ônibus, etc.), não sendo aproveitadas como uma fonte de construção cidadã e ampliação da leitura de mundo.

A partir dos dados analisados podemos afirmar a existência da Exclusão Escolar Oculta através da desconsideração dos saberes comunitários na escola. Os saberes comunitários, as idéias, os pensamentos, as reflexões e as sugestões das crianças eram desconsiderados nos momentos de planejamento e avaliação das turmas pesquisadas. Nas duas, a sala de aula era, como já explicitado, o espaço das professoras e seus conhecimentos, ao qual as crianças deveriam se adequar e onde deveriam permanecer em silêncio para aprender conteúdos, não possuindo qualquer relação com a realidade em que viviam.

No nosso entendimento, ficou muito claro que o sentido da alfabetização de Fiori estava longe das turmas observadas. Nesses espaços, o trabalho de alfabetização desenvolveu-se através da escrita de palavras, que não eram as conhecidas na comunidade. A produção textual não foi utilizada em nenhuma das duas turmas. Conforme observado, a aprendizagem não tinha muito sentido para elas. Acreditavam que serviria para o futuro, mas esse estava distante e também não compreendiam muito bem em que esse conhecimento iria ajudá-las.

Ao pensar sobre as duas turmas acompanhadas durante a pesquisa, fazemos nossas as palavras de Freire (2000c) quando pensamos nos espaços que supostamente deveriam ser de interação com o conhecimento: 


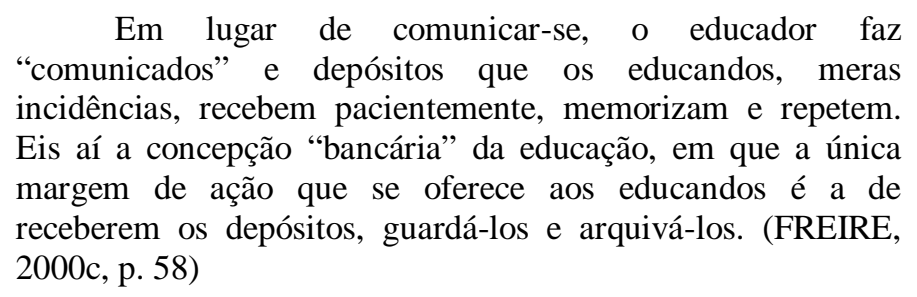

A concepção bancária hipoteticamente superada na Rede Municipal de Ensino de Porto Alegre permanece oculta como demonstrou nossa pesquisa. Concepção bancária essa que exclui e condiciona as pessoas a uma situação de miséria e "ingenuidade". Concepção bancária oculta que demonstrou que ainda não há espaço e nem relações entre os saberes comunitários e os conteúdos escolares.

\section{Referências bibliográficas}

BRASIL. Lei n. 8069/1990. Estatuto da criança e do adolescente (ECA). Brasília, 1990.

BRASIL. Lei n. 9394/1996. Lei de Diretrizes e Bases (BRASIL). Brasília, 1996.

DORNELES, Beatriz Vargas. Mecanismos Seletivos da Escola Pública: um estudo etnográfico na periferia de Porto Alegre. 1986. Dissertação (Mestrado) - Programa de Pós-graduação em Educação da Universidade Federal do Rio Grande do Sul, Porto Alegre, 1986.

FREIRE, Paulo (1999). Pedagogia da Autonomia: saberes necessários à prática educativa. São Paulo: Paz e Terra.

FREIRE, Paulo (2000a). Pedagogia da Esperança: um reencontro com a pedagogia do oprimido. São Paulo: Paz e Terra.

FREIRE, Paulo (2000b). Pedagogia da Indignação. São Paulo: Editora Unesp.

FREIRE, Paulo (2000c). Pedagogia do Oprimido. Rio de Janeiro: Paz e Terra.

FREIRE, Paulo; BETTO, Frei (2001). Essa Escola Chamada Vida: depoimentos ao repórter Ricardo Kotscho. São Paulo: Editora Ática. 
FREIRE, Paulo; NOGUEIRA, Adriano (2001). Quer Fazer: teoria e prática em educação popular. Petrópolis: Editora Vozes.

PATTO, Maria Helena de Souza (1991). A Produção do Fracasso Escolar: histórias de submissão e rebeldia. São Paulo: T. A. Queiroz.

PIAGET, Jean (1994). O Juízo Moral na Criança. São Paulo: Summus.

PICETTI, Jaqueline Santos. Movimentos de Exclusão Oculta. 2002. 152 f. Dissertação (Mestrado) - Programa de Pós-graduação em Educação da Universidade Federal do Rio Grande do Sul, Porto Alegre, 2002.

SMED - Secretaria Municipal de Educação (1999). Ciclos de Formação: proposta político-pedagógica da escola cidadã. Cadernos Pedagógicos, Porto Alegre.

\section{Autoras}

\section{Jaqueline Santos Picetti}

Doutoranda em Educação - PPGEDU/UFRGS. Secretaria Municipal de Educação de Porto Alegre. Supervisora Escolar e Professora. jaquelinesantospicetti@yahoo.com.br

\section{Luciane Magalhães Corte Real}

Doutoranda em Informática na Educação - PGIE/UFRGS. Universidade Federal do Rio Grande do Sul. Professora Assistente de Psicologia da Educação.

lucreal@orion.ufrgs.br

\section{Como citar este artigo:}

PICETTI, Jaqueline Santos e REAL, Luciane Magalhães Corte. A relação entre os saberes comunitários e os conteúdos escolares no processo de alfabetização. Revista ACOALFAplp: Acolhendo a Alfabetização nos Países de Língua portuguesa, São Paulo, ano 2, n. 3, 2007. Disponível em: <http://www.mocambras.org > e ou <http://www.acoalfaplp.org>. Publicado em: setembro 2007. 